\title{
Stärker und doch schonend bestrahlen
}

Liegt bei der Therapie des lokalisierten Prostatakarzinoms die Zukunft in der hypofraktionierten

Bestrahlung? „Seit etwa dem Jahr 2000 weiß man, dass die Verwendung höherer Einzeldosen an der Prostata zu klinisch besseren Ergebnissen führen kann und dass das benachbarte Normalgewebe diese geänderten Dosiskonzepte verträgt", betonen Heinrich Seegenschmiedt und Kollegen vom Strahlenzentrum Hamburg in einem zertifizierten Fortbildungsbeitrag [Im Focus Onkologie. 2015;18(12):54-62]. Wie sehr es bei einer "External Beam Radiation Therapy" (EBRT) auf rektumschonende Maßnahmen ankommt, zeigen Vergleiche von Radioonkologen der Paracelsus Medizinischen Privatuniversität Salzburg (Abb. 1) [Wolf F et al. Radiother Oncol. 2015;116(2):221-59]. Zur Rektumschonung eignen sich neben anderen Methoden spezielle Spacer (z, B. Abb. 2).

Martin Roos

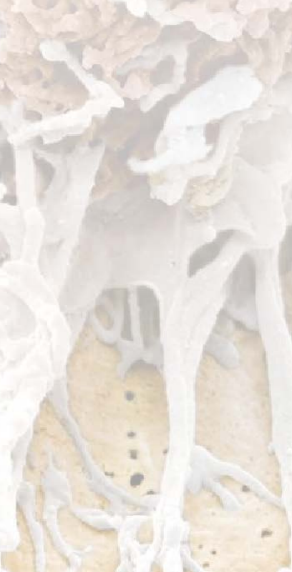

Abb. 1: Sowohl Ballonspacer (oben links) als auch Gelspacer (rechts) reduzieren die Rektumbelastung (unten: keine Rektumschonung). Die Prozenteskala bezieht sich auf die Dosisverteilung im Rektum.
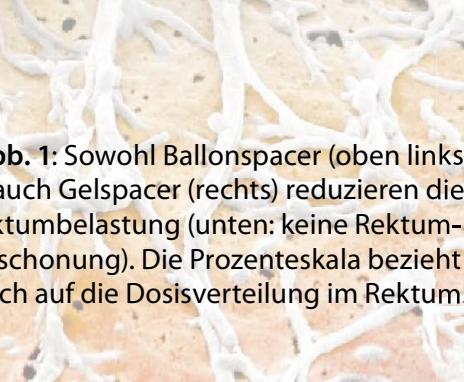
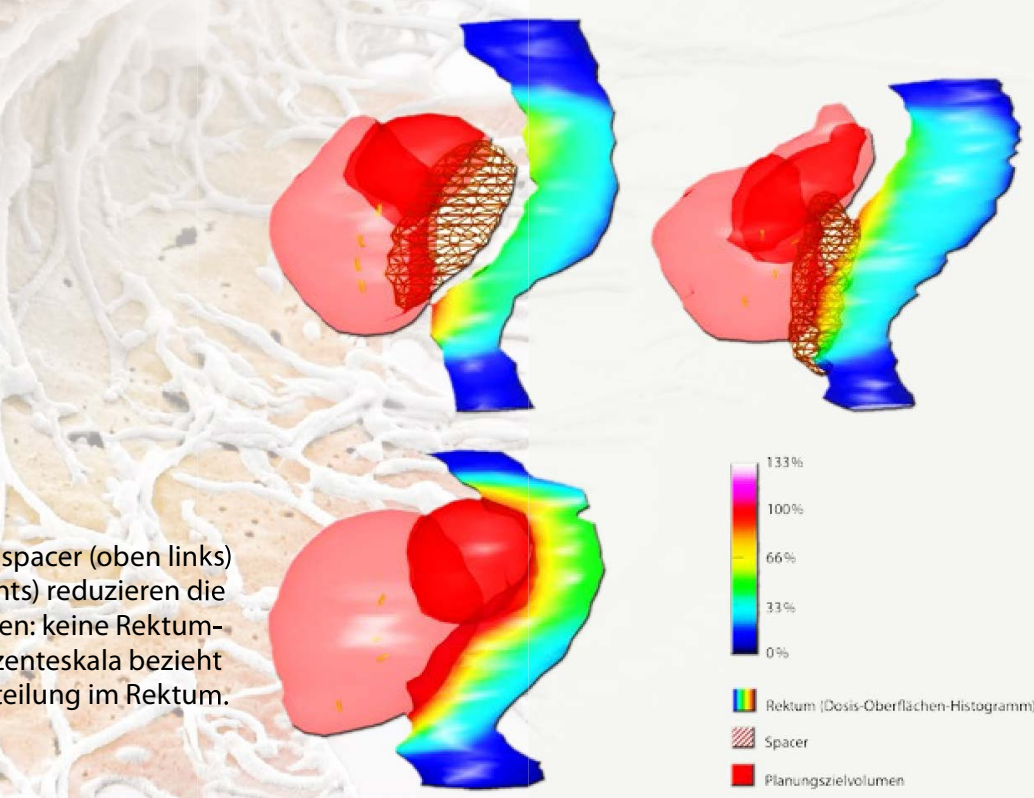

$\amalg$ Rektum

$\not 4$ spacer

2as spact
Abb. 2: Der mit Kochsalzlösung gefüllte Spacer (weiß) bringt das zu bestrahlende Prostatagewebe (oben) in deutlichen Sicherheitsabstand vom Rektum (unten). 